\title{
Therubber squareillusion
}

\author{
A ilusão do quadradoflexível
}

Fauzia Mosca ${ }^{1,2}$

Nicola Bruno 2

${ }^{1}$ Università di Trieste; ${ }^{2}$ University of Liverpool. Correspondence concerning this article should be addressed to Nicola Bruno, Dipartimento di Psicologia, Università di Trieste - Via S. Anastasio 12, 34143 Trieste, Italy (email: nicola.bruno@univ.trieste.it).

\section{A BSTRACT}

We report a new illusion of elasticity in a rigid surface. A square frame is presented behind a concentric occluding cross. When the two surfaces are rotated rigidly, the square frame appears "rubbery", that is, it appears to contract or expand during the rotation. The rubber square illusion is related to a number of other illusory phenomena involving motion and surface stratification. It is generally believed that these phenomena are due to suppression of potentially veridical motion signals at t-junctions signalling occlusions. However, in all previously reported phenomena the effect of t-junctions was confounded with effects due to surface relative motion, spatial integration, or relative contrast. Given that none of these potential confounds applies to our demonstration, the rubber square illusion provides critical evidence that $t$-junctions are sufficient to cause suppression of the corresponding motion signals.

Keywords: Vision; Motion; Integration; Segmentation; Depth; Illusions

We report a new illusion of elasticity in a physically rigid moving surface. Consider figure 1 and imagine that the pattern (both the grey and the black regions) is smoothly rotated as a whole around its center by about $30 \mathrm{deg}$, first in one direction and then back to its original position, through several cycles. Clearly, neither the square nor the black occluding surface undergo any change in size as they undergo these cyclic moviments. However, the occluded grey square frame appears elastic, as if it were contracting and expanding. These contractions and expansions are slight but clearly visible: We have shown the rubber square illusion to a number of visitors and students in our laboratory and we have not found a single observer who did not report it spontaneously. The lack of rigidity of the rotating square is illusory and wholly paradoxical. An obsever can readily become aware of this when fixating one of the sides of the square while attentively ignoring the remainder of the display. When the display is observed as a whole, however, the expansions and contractions become immediately salient.

\section{Relationships to known motion illusions}

The rubber square illusion is related to a number of known illusions whereby processes involved in detecting and identifing surface boundaries from spatiotemporally sparse information undergo partial failures. Such failures are generally understood as providing useful constraints on theories of spatiotemporal boundary formation ${ }^{(1)}$ and on neural models of motion integration that are sensitive to the spatial structure of the stimulus ${ }^{(2-3)}$. Specifically, these models call for a fundamental distinction between three kinds of motion signals: perpendicular signals available along contours due to the aperture problem ${ }^{(4)}$, unambiguous signals at true contour termina- 


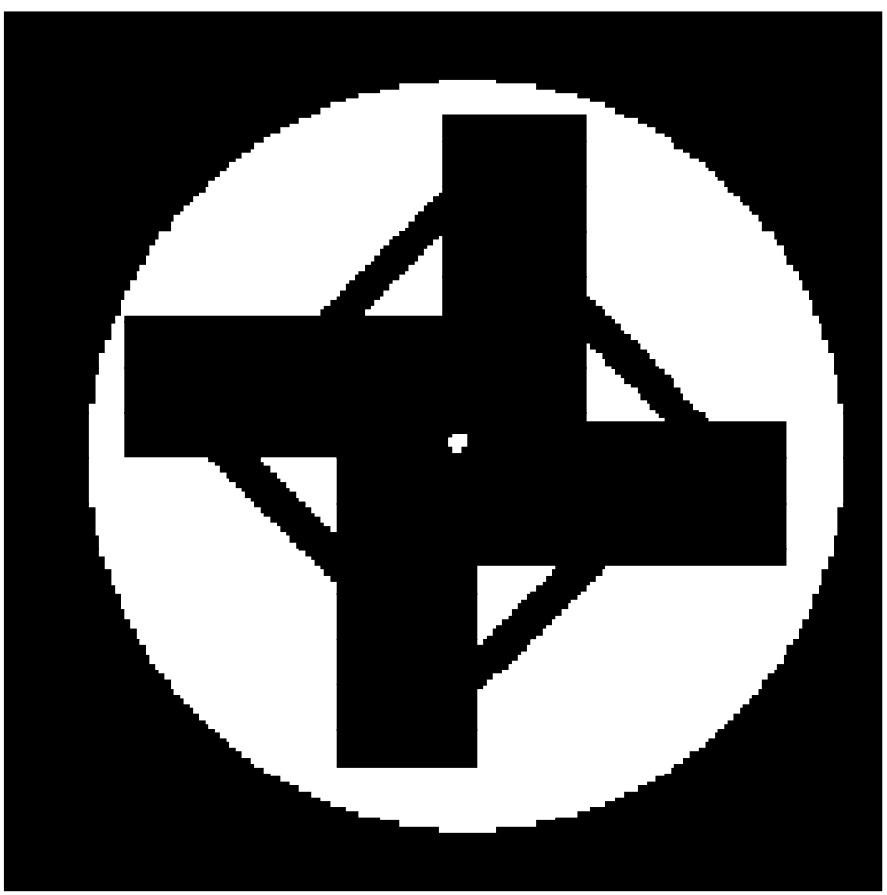

Figure 1 - The rubber square illusion. When the center pattern is rotated back and forth over the white background, the occluded square frame appears rubbery - it seems to shrink and expand during the rotation. The illusion can be experienced by photocopying the present page and the placing the figure on a slow rotor. Alternatively, a computer animation can be seen at the following URL: http://www.psico.univ.trieste.it/labs/perclab/rubber.

tors $^{(5)}$, and signals at spurious contour terminators ("t-junctions") that are associated with surface occlusions. The observation that edge terminators that are perceived as being caused by occlusion tend to be excluded from the computation of edge motion is not new ${ }^{(4,6-7)}$ but opinions on the interpretation of such observations are still divided ${ }^{(3,8-10)}$. For the purpose of the present report, it will be useful to divide this class of illusions into two main categories: illusions involving relative motion between the occluding and the occluded surface, and illusion involving no relative motion.

The first category (relative motion between occluder and occluded surfaces) includes a number of animation displays with the following characteristics: one or more stationary occluding surfaces, one rotating occluded surface, stimulus conditions favoring a clear impression of surface stratification, and a strong impression that the occluded surface changes its size while rotating ${ }^{(11-14)}$. Given that the change in size is often described as a surface that pulsates or "breathes", this class of illusions has been termed the breathing illusions (for a review $\left.{ }^{(15)}\right)$. It has been proposed that breathing illusions are caused by a failure to properly integrate motions signals specifying surface rotation, presumably, because spurious terminators at points of occlusion are prevented to spread along the contours of the rotating figure ${ }^{(16-18)}$ and the center of rotation of such contours is misperceived ${ }^{(14)}$. However, it has been noted that purely spatial processes of boundary formation may also be involved in the illusion, in that the formation of boundaries tend to obey a monotonicity constraint ${ }^{(19-20)}$. Applying such contraint to an occluded corner, one would predict that the interpolation would not yield an angle, but a smooth curve. Thus, the interpolated size of a surface having its corners covered by an occluder would be predicted to be smaller than the size of the same surface when the corners are fully visible. Thus, as the occluded surface undergoes the transition from corners occluded to corners visible, one might expect that the surface will appear to grow ${ }^{(15)}$. It remains presently unclear whether such spatial factors are the main determinants of the breathing impression, or merely contribute to it along with constraints on the spatiotemporal integration of motion signals according to spatial structure.

The second category (no relative motion) consists of variations on an illusion discovered by Gerbino \& Bruno ${ }^{(21)}$. Imagine that, instead of the black pattern of Figure 1, the figure occluding the grey square were a black cross. When this cross is rotated with the underlying square, the square appears stationary or almost stationary, and then to jump every now and then to a new position. This is a visual paradox, in that observers are fully aware that the square is indeed rotating solidly with the occluding cross. If it were not, then its vertices should be revealed at some point but they never are. However, and especially when one fixates the center of the cross, most of the time the square appears at rest or to move more slowly than the cross. A natural explanation for the paradoxical rest in Gerbino \& Bruno's rotary display is along the following lines. If the square is well segmented from the occluding cross, the unambiguous rotation signals that are potentially available at the t-junctions between the square and the cross should not spread to the square edges. Given the position of the visible parts of the square relative to the rotation trajectories, the orthogonal components are zero or minimal, and therefore one could expect that the square would tend to appear stationary. Gerbino \& Bruno $^{(21)}$ presented arguments in support of this interpretation by varying figural segregation with contrast manipulations. However, it could be that the apparent rest of the square is simply due to the weakness of the corresponding motion signals relative to those of the occluding edges.

\section{Theoretical import of the present illusion}

Thus, in both categories of previously known illusions the illusory effect may be explained by an occlusion effect on motion integration, but other explanations are also possible. We suggest, however, that these alternative explanations do not apply to the rubber square illusion unambiguously and herein lies its theoretical importance. In the rubber square illusion, no relative motion is present between the occluding pattern and the occluded square that appears rubbery. Hence, no corners are ever revealed nor is the amount of occluded contour ever modified. Therefore, processes of spatial interpolation provide no basis for predicting changes in size, however slight. At the same time, however, motion signals specifying square rotation are obviously above threshold and 
strong enough to cause observer to see changes over time (although this change is attributed in part to an illusory deformation). Thus, there is no reason to ascribe the illusion to diferences in contrast.

Although our purpose here is simply to report our observation, not to test hypotheses about its explanation, a natural possibility is that the elastic motion perceived in the rubber square illusion simply corresponds to the local orthogonal components at the contour of the square frame. Because the visible parts of this frame are off the center of the square side, during the rotation the corresponding contours do indeed have orthogonal components that are all oriented away or toward the center of rotation. Note, however, that the mere presence of these components is not an explanation of the illusion, because such components are present also on all the contours of the black occluding pattern, which does not appear rubbery. In the case of the black pattern, presumably, unambiguous rotation signals from the pattern corners can spread along the contour, and thereby neutralize the orthogonal components ${ }^{(3,5)}$. However, corners are also formed by the grey segments and the contours of the black pattern. In fact, when compared with the rotation signals from the corners of the black pattern, rotation signals from the grey-black intersections would have to travel shorter distances in order to spread to the grey contour. In addition, unambiguous motion signals are also provided by the displacement of the grey segments relative to the stationary checkerboard pattern. These would also have to travel very short distances to spread on the contour. Given that alternative explanations that could account for related illusions can be ruled out here, it seems quite plausible that the reason why abundant veridical signals fail to spread to along the contour lies in a suppression mechanism linked to t-junctions and surface occlusion.

\section{Additional observations}

A simple demonstration of the rubber square illusion is available on the world-wide-web at the URL http://www. psico.univ.trieste.it/labs/perclab/rubber. A fully interactive animation that runs on an SGI machine can be obtained from the authors upon request. The current version includes the possibility of varying the spatial and chromatic characteristics of the display and of adding stereodepth.

Based on our own observations, the rubber square illusion is somewhat more compelling when the black pattern is placed in front of the square frame by means of binocular disparity or when observing the animation monocularly. This seems to imply a mechanism for classifying edge terminators that is capable of pooling occlusion information from both t-junctions and binocular information. Alternatively, the difference may be due to conflict of t-junctions with binocular disparity when observing the pictorial sequence with two eyes. We have also noted that the contraction/expansion effect is somewhat stronger when the square pattern is a thick frame rather than a filled surface. The greater illusory strength of the frame version over the filled square version may be due to figura 1 factors that "glue" the occluded filled square to the occluding black pattern, or perhaps to a more salient lack of configural change $^{(22)}$ of the filled visible portion of the square, specifying rigid rotation. These factors may explain the difference with the effect of a similar manipulation on the illusion studied by Shiffrar \& Pavel ${ }^{(14)}$, which contained such configural change due to relative motion between the occluding and the occluded surface. The contraction/expansion effect also increases with the eccentricity of the frame. This is consistent with the hypothesis that the effect corresponds to the inward/outward orthogonal components, which become stronger as a function of distance from the center of rotation.

On the other hand, and quite strikingly, the effect is not weakened by the addition of a stationary frame of reference such as a background checkerboard instead of the homogeneous field in figure 1 . Thus, although adding a background checkerboard greatly increases the number of t-junctions that could capture the motion of the rotating edge, these junctions appear to be suppressed exactly in the same fashion as those at the point of occlusion with the overlying cross. Finally, we have observed that a related illusion is experienced when, instead of rotating back and forth, the center pattern rotates steadily always in the same direction. In this latter case, the square appears to contract or expand always in the same direction, depending on the verse of rotation. We found this form of the illusion even more paradoxical, in that we were fully aware that the square was not deforming during the rotation, and yet experienced the inward or outward component. Perhaps for this reason, this form of the illusion appears somewhat weaker than the standard version described earlier. The decrease in illusory strength observed during unidirectional as opposed to back-and-forth rotation may be due to motion signals derived from ocular pursuit ${ }^{(23)}$, or to temporal contrast between the inward and outward motion of the rubbery square which may enhance the visibility of the orthogonal components.

\section{RESUMO}

Nós relatamos uma nova ilusão de elasticidade de uma superfície rígida. Uma moldura quadrada é apresentada atrás de uma cruz concêntrica ocludente. Quando as duas superfícies são rotacionadas rigidamente, a moldura quadrada aparenta flexibilidade, qual seja, ela parece contrair e expandir durante a rotação. A ilusão do quadrado flexível é relatada em inúmeras outros fenômenos ilusórios envolvendo estratificação de movimento e de superfícies. Acredita-se que estes fenômenos são devido à supressão de sinais de movimento potencialmente verídicos nas junções em T sinalizando oclusões. Entretanto, em todos os fenômenos previamente relatados, o efeito das junções em $\mathrm{T}$ foram confundidos com os efeitos relacionados ao movimento relativo, integração espacial, ou contraste relativo. Dado que nenhuma destas potenciais confusões se aplica à nossa demonstração, a ilusão do quadrado flexível forne- 
ce evidência crítica em favor de que as junções em $\mathrm{T}$ são suficientes para gerar a supressão dos sinais de movimento correspondentes.

Descritores: Visão; Movimento; Integração; Segmentação; Profundidade; Ilusões

\section{REFERENCES}

1. Shipley TF, Kellman PJ Spatio-temporal Boundary Formation: the Role of Local Motion Signals in Boundary Perception. Vision Res 1997;37:1281-93.

2. Grossberg S, Mingolla E, Viswanathan L. Neural dynamics of motion integration and segmentation within and across apertures. Vision Res 2001;41: 2521-33.

3. Linden L, Pack C. The role of terminators and occlusion cues in motion integration and segmentation: a neural network model. Vision Res 1999;39: 3301-20.

4. Wallach H. Über visuell wahrgenommene Bewegungsrichtung. Psychol Forscheung 1935;20:325-80. (Translation Wuerger S, Shapley R, Rubin N. On the visually perceved direction of motion by Hans Wallach: 60 years later. Perception 1996;25:1317-67).

5. Adelson EH, Movshon JA. Phenomenal coherence of moving visual patterns. Nature 1982;300:523-5.

6. Metelli F. Ricerche sperimentali sulla percezione del movimento. Riv Psicol 1940;36:319-60.

7. Metelli F. Zur theorie der optischen bewegung swahrnehmung berig. Über den 24 kongress der deutshen geswschaft fur psychologie (Wien, 1964). Gottigen: Hogrefe; 1965.

8. Shimojo S, Silverman GH, Nakayama K. Occlusion and the solution to the aperture problem for motion. Vision Res 1989;29:619-26.

9. Trueswell JC, Hayhoe MM. Apertures only constrain motion of figures not ground. Invest Ophthalmol Vis Sci 1993;S34:1230.
10. Castet E, Charton V, Dufour A. The extrinsic/intrisic classification of 2D motion signals with barber-pole stimuli. Vision Res 1999;39:915-32.

11. Bruno N, Gerbino W. Illusory figures based on local kinematics. Perception 1991;20:259-74.

12. Meyer GE, Dougherty TJ. Sawtooth Pac-People and the realization of illusory edges: Computational, cognitive, and utilitarian implications. Paper presented at the Annual Meeting of the Psychonomic Society, Seattle; 1987.

13. Meyer GE, Dougherty TJ. Sawtooth "pacpeople", fuzzy illusory edges and contours that contract. Perception 1988;Suppl:17.

14. Shiffrar M, Pavel M. Percepts of rigid motion within and across apertures. J Exp Psychol Hum Percept Perform 1991;17:749-61.

15. Bruno N. Breathing illusions and boundary formation in space-time. In: Shipley T, Kellman P, editors, From Fragments to objects: Segmentation and grouping in vision. Amsterdam: Elsevier; 2001.

16. Lorenceau J, Shiffrar M. The influence of terminators on motion integration across space. Vision Res 1992;39:859-71.

17. Shiffrar M, Li X, Loreanceau J. Motion integration across differing image features. Vision Res 1995;35:2137-46.

18. Shiffrar M. The visual intepretation of object and human movement In: Shipley T, Kellman P, editors, From Fragments to objects: Segmentation and grouping in vision. Amsterdam: Elsevier; 2001.

19. Kellman PJ, Loukides MG. An object perception approach to static and kinetic subjective contours. In: Petry S, Meyer GE, editors, The perception of illusory contours. New York: Springer-Verlag; 1987.

20. Shipley TF, Kellman PJ. Spatiotemporal boundary formation: Boundary, form, and motion perception from transformations of surface elements. J Exp Psychol Gen 1994;123:3-20.

21. Gerbino W, Bruno N. Paradoxical rest. Perception 1997;26:1549-54.

22. Wallach H, O'Leary A. Vector analysis of rotary motion perception. Percept Psychophys 1935;38:47-54.

23. Wallach H. Eye movement and motion perception. In: Wertheim AH, Wagenaar VA, Leibowits HW, editors, Tutorials on Motion Perception. New York: Plenum; 1982, p.1-18. 